\title{
Teaching Style Differences between Male and Female Science Teachers in Qatari Schools: Possible Impact on Student Achievement
}

\author{
Ahmad A. El-Emadi ${ }^{1}$, Ziad Said ${ }^{2}$, Heather L. Friesen ${ }^{3}$ \\ ${ }^{1}$ Qatar University, QATAR \\ ${ }^{2}$ College of the North Atlantic, QATAR \\ ${ }^{3}$ Abu Dhabi University, UNITED ARAB EMIRATES
}

Received 10 April 2019 • Revised 7 May 2019 • Accepted 8 May 2019

\begin{abstract}
In Qatar's gender-segregated public schools, female students outperform male students in international science tests such as PISA and TIMMS. In contrast to the international trend for top performing countries, however, female students report lower levels of interest in science-based careers than males. One possible factor that may contribute to this discrepancy is the difference in teaching styles between female teachers and their male counterparts. In this paper we focus on results obtained from 105 classroom observations (39 males and 66 females) selected from 50 different public schools as part of two independent research projects to study the motivation factors and attitudes toward and interest in science among Qatari students. In addition, 40 semi-structured interviews of students, teachers and administrators were conducted. The observations were guided using an adopted Reformed Teaching Observation Protocol (RTOP) evaluation rubric consisting of 13 teaching traits which provides a standardized mean for detecting the degree to which science classroom instruction is reformed through a focus on Lesson Design, Content, Pedagogic Knowledge and classroom culture. Female teachers provided better delivery during theory classes, whereas male teachers demonstrated better performance in laboratory-based classes.
\end{abstract}

Keywords: teaching style, attitude, delivery skills, male teachers, female teachers

\section{INTRODUCTION}

Student decisions about study and career paths are based primarily upon interest in a particular field, and particularly on their perception of job prospects in that field. Educational content and curricula play important roles in raising and maintaining young people's interest in science and technology, and positive contact with science and technology at an early age can have a long-lasting impact. Negative experiences at school, due to uninteresting content or poor teaching and various other factors, often inform future choices. Additionally, curriculum structures that do not motivate students, and that lack practical investigation and problem solving, can also play an important role in preventing students from pursuing their natural preferences (Hofstein \& Lunetta, 2004; Maltese \& Tai 2011; Millar \& Abraham, 2009; Russell \& Weaver 2008).

Over the years, science educators have identified multiple variables influencing attitudes toward science (Gardner, 1975; Koballa, 1995; Osborne et al., 2003; Schibeci, 1984). Specifically, Gardner (1975) and Schibeci (1984) identified gender, personality, grade level, geographic location, socioeconomic status, cultural background, teaching strategies, and curriculum materials as being strongly influential on attitudes towards science.

Of these variables, Gardner (1975) and Schibeci (1984) suggest that gender is the strongest and most consistently influential. The nature of this influence, however, has been contradicted by different studies. Early studies found that males hold consistently more positive attitudes toward science than females (Simpson \& Oliver, 1985, 1990; Weinburgh, 1995), but more recent studies have reported that females are more positive in their attitudes (Boone,

(C) 2019 by the authors; licensee Modestum Ltd., UK. This article is an open access article distributed under the terms and conditions of the Creative Commons Attribution License (http://creativecommons.org/licenses/by/4.0/). \ded3aga@qu.edu.qa $\$ ziad.said@cna-qatar.edu.qa (*Correspondence) $\$ heather.friesen@adu.ac.ae 


\section{Contribution of this paper to the literature}

- This work contributes to the literature on teaching styles of male and female science teachers in Qatar.

- It identifies that female teaching styles in gender-segregated schools may motivate female students in science classes and result in improved academic performance.

- It combines quantitative aspects based on analyses of observations of theoretical and practical classes in schools of both genders with qualitative analysis based on in-depth interviews of students, teachers, and administrators.

1997; Murphy \& Beggs, 2003). Observed gaps are stronger in physics and earth sciences than in biology and "life science" or general science (Murphy \& Beggs 2003; Steinkamp \& Maehr, 1983).

As part of a wider study of OECD countries entitled The Relevance of Science Education (ROSE), Sjøberg \& Schreiner (2010) concluded that "young people are not enthusiastic about school science - in particular not the girls" and "in wealthy countries very few want to become scientists - in particular not the girls" (p. 14).

Griffith (2014) found that although major choice and course-taking behavior are mostly unaffected by the gender match between faculty and student, students earn higher grades in courses taught by same-gender instructors in fields traditionally dominated by the opposite gender such as STEM.

Positive attitudes towards subjects are developed through personal support from teachers and family, effective use of a variety of teaching strategies, innovative learning activities, and student-centered instructional design (French \& Russell 2006; Jarvis \& Pell, 2005). Previous studies have reported a decline in students' attitudes toward science as they approach secondary school (Farenga \& Joyce, 1998; Kelly, 1986; Pell \& Jarvis, 2001; Said, 2014; Speering \& Rennie, 1996; Yager \& McCormack 1989). This decrease is especially pronounced for females (Greenfield, 1997). Lovelace and Brickman (2013) reviewed several research studies on attitudes and students' motivation which show that "students' perceptions of courses and attitudes toward learning play a significant role in retention and enrollment. Motivation has a strong direct effect on achievement, and, in some courses, students' attitudes may provide a better predictor of success than quantitative ability." (p. 606).

In Qatar's public schools, female students outperform their male counterparts in national and international tests (Mullis et al., 2016) despite their perceived lower interest in further studying science at tertiary education or pursuing a science related career (Said, 2016, Said et al., 2016, 2018) . In PISA 2015, Qatari students scored in the bottom one-quarter of the 70 systems assessed worldwide. Although significant progress has been demonstrated in comparison with previous cycles, both female and male Qatari students score relatively low; however, the females score significantly higher than the males (OECD, 2018a), with PISA noting that, in the Qatar perspective, "the difference between boys and girls in science performance is one of the largest among PISA-participating countries and economies in favour of girls" (OECD, 2018b).

Both TIMMS and PISA reported that on their indices of "enjoyment of learning science" Qatari students scored significantly above the international average (Martin et al. 2016 and OECD, 2016b). However, significant differences were not observed between the two genders in interest and attitude toward science during two longitudinal studies conducted among all students in Qatar from primary to university level (Said, Summers, Abd-el-Khalik \& Wang, 2016b; Said, Al-Emadi, Friesen \& Adam, 2018).

BouJaouda and Gholam (2013) found that in the Arab world in general, due to sociocultural factors, girls are less likely to aspire to a STEM career than boys, while Abdulwahed, Ghani, Hasna and Hamouda (2013), and Sellami, Kimmel, Wittrock, Hunscher, Cotter and Al-Emadi (2017) found the opposite in Qatar, where girls' aspiration is significantly higher than that of boys. The latter researchers concluded that "the individual attributes and attitudes, including gender and educational aspirations and motivation, are the main drivers behind students' career expectations"; but they do not mention what these motivation factors might be.

Morse and Handley (1985) suggested that the differences in male/female teacher/student interaction are affected by subject matter being taught and other factors associated with classroom environment (grade level, subject matter, student socioeconomic status). They observed that during grades 7 and 8 science classes, females initiated fewer questions and provided fewer responses to questions than males. In addition, they found that teachers interacted more with males than females.

Brophy (1986) indicated that students achieve more when their teachers emphasize academic objectives in establishing expectations and allocating time, use effective management strategies to ensure that academic learning time is maximized, and adapt curriculum materials based on their knowledge of students' characteristics. He indicates that teachers differ in how they perform such instructional behaviors as giving information, asking questions, and providing feedback. He concluded that any attempt to improve student achievement must be based on the development of effective teaching behavior. 
The PISA and TIMMS results, which indicated outperformance of Qatari female students in all cycles, could not be completely explained on the basis of attitude towards science and aspiration to STEM careers, otherwise, students from Korea and Japan, for example, wouldn't be at the top of achieving countries as their attitudes and interest are much lower than Qatar which is at the lower third of the list as mentioned above. This implies that other factors, such as teacher/male and teacher/female student interaction may contribute as well.

Instructional strategies and teaching styles would be among these factors, especially in gender-segregated public schools. This paper explores the general features of instructional science practices and teaching styles of male and female teachers in Qatari gender-segregated public schools.

\section{Difference in Teaching Styles and Practices}

Teachers serve as role models for their students' learning. Students learn best from teachers they respect and with whom they have developed a good relationship. Research indicates that positive relationships with teachers enhances students' confidence and feelings of competence, which in turn has a positive influence on student learning. Teacher support also enhances the positive effect of student engagement. Given that females, generally speaking and especially at advanced grades, feel less competent than males in science, the teacher's role is a critical influencer female students' learning and engagement.

Currently, there is sparse research that examines the factors behind the difference between gender performance in general, and particularly in science. Several studies indicate that there is no significant difference in teaching styles between male and female teachers (Centra \& Gaubatz 1998; Feldman, 1992; Francis et al., 2006; Islahi \& Nasreen, 2013; Mullola et al., 2011, whereas others examin the effect of gender match between teacher and students on achievement and engagement (Dee, 2005, 2007; Winters et al., 2013)

Lim and Meer (2015) analyzed data from 197 middle schools in South Korea, and concluded that female students perform better in standardized tests in some subjects such as language and arts when they have a female teacher, but there is little same-gender teacher effect for males. They suggested that teacher behavior drives this increase in student achievement and highlighted stronger interactions between female teachers and students. Other studies claimed that male teachers are perceived by students as more knowledgeable, while female teachers are considered more student-centered and respectful (Basow, 1999; Lacey et al., 1998).

Ibe et al. (2013) found a significant difference in the perceived knowledge and familiarity of male teachers with laboratory equipment compared with that of females. They labelled 71 chemical laboratory apparatus and glassware items, and asked 454 male and female teachers from 227 schools in Nigeria, to identify the names and uses of these items. Results indicated that male teachers' knowledge, generally speaking, was higher than that of their female counterparts.

Gilmartin et al. (2007), explained the effect of increasing percentage of female science teachers on dimensions of students' science identities, and stated that "female science teachers introduce students into 'figured worlds" of school science within which they play largely supporting roles". Dee (2006), suggested that "boys perform better when taught by male teachers and girls perform better when taught by female teachers". In contrast, Martin and Marsh (2005) believe that motivation is more of a student factor than a teacher factor, and the greatest results are achieved as a result of individual efforts and motivation.

In a survey of 220 primary school teachers, Wood (2012) concluded that differences between female and male elementary teachers are unclear in many areas, with no significant quantitative differences in perceptions of females and males; however, qualitative differences exist, with males receiving more negative comments than their female colleagues in relation to the effective nurturing of students.

Some educators agree that women in general are better teachers based on their experience as mothers. Carrington et al. (2008) suggest that students taught by female teachers had more positive attitudes toward school, but questioned if that may apply to subjects such as science that are more associated with cognitive knowledge and certain skills which are affected by more than one domain such as cognitive (thinking), affective (feeling) and psychomotor (doing) domains as explained by Novak, 2011 and Galloway and Bretz (2015).

Martha et al. (2015) explained that "the proportion of female math and science teachers at a school has no impact on male students, but it has a powerful effect on female students' likelihood of declaring and graduating with a STEM degree". External factors such as school environment, teachers' education and training, and sociocultural factors may contribute, at least partly, to this difference in teaching styles of both genders. No published research has previously compared such styles based on in depth observations in the class room.

In this paper we present results generated from direct observations of 105 science teaching classes from 50 Qatari schools as part of two research projects to explore further the factors that motivate students and enhance their attitudes toward science, to shed light on the way science is communicated at different schools, and to find out if 
strategies of science delivery vary among gender-segregated schools. The study was guided by the following research questions:

1. What are the general features of male and female science teachers' teaching styles in public Qatari schools? Do common features exist among teachers of the same gender that differ from those of the other?

2. By which gender do male and female students prefer to be taught, and why?

\section{BACKGROUND}

The two above-mentioned projects are briefly described below

1. Qatari students' Interest in, and Attitudes towards, Science (QIAS) project: In this project, 1,800 Qatari students at the preparatory, secondary, and university levels were surveyed about their interests, attitudes, and self-efficacy regarding science. Findings (Said, Al-Emadi, Friesen, \& Adam, 2018) suggest that while Qatari students are positive in their interests, attitudes, and self-efficacy, they do not translate to outcomes in TIMSS and PISA reports, and there exists no statistically significant difference in these variables between male and female students; additionally, the findings indicated that science career interest was particularly low among female students. The findings raised two questions: first, if the students' interest, attitude, and self-efficacy are positive, then why do students have relatively low achievement scores on TIMSS and PISA? Second, why there is a significant difference, as previously mentioned, between the achievement of females and males in favour of females which is opposite to the general universal trend of most countries? The answer may be the instructional methods and conditions of a developing educational system.

2. Effective Delivery of Practical in Science (EDPS) project: This was part of a project entitled "Development of a Framework for Practical Science in Alignment with Curriculum Standards of Grades 3-12 of Schools in Qatar". The goal of this project was to identify factors that encourage the delivery of quality practical work (hands-on lab experiments, virtual labs, models or other related activities such as use of posters, charts and other secondary data) in school science in addition to those barriers that may inhibit it, to develop a framework to encourage and support the effective use of practical work in school science in Qatar aligned to the national science curriculum standards, and to propose a strategy for implementation. Previous research indicates that there is a lack of sufficient application of practical activities in science classes in Qatari schools. One reason is that many teachers are not adequately trained to effectively deliver practical components. In a previous science inventory survey (Said, 2016), it was revealed that the majority of Qatari schools employ laboratory technicians who are not professionally trained in implementing laboratory tasks consistent with science education reform. In addition, the number of technicians is not adequate to handle the increasing number of students in the school system, with a particular deficiency evident in female schools.

As part of the project, teachers from 22 schools were enrolled in extended training courses (four hours per week for 16 to 18 weeks during the academic year) covering the effective delivery of practical science lessons in alignment with science curriculum standards. Each course was designed to train teachers on practical and pedagogic techniques to enhance activities, in a way that allowed teachers to practice each activity during the training before delivery to their students. Teachers would then reflect on their teaching and discuss feedback with their trainers and colleagues in the subsequent training session. Evaluation of the program was based on three elements: 1) Trainees' performance before and after training, 2) student performance in standardized tests before and after training, and 3) an assessment of students' attitudes toward science before and after training compared to students from control schools. Results indicated a positive impact was demonstrated for both genders in all three elements; however, female students' attitudes toward practical activities was significantly less positive than males, possibly reflecting a different approach in practical classes' delivery (Said, Anwari, Al-Shahrouri \& Adam, 2018c).

\section{METHOD}

\section{Research Methodology}

This study employed a mixed methodology, with quantitative analyses based on class observations and qualitative analyses based on semi-structured interviews. The selection of mixed methods has the advantage of achieving stronger generated inferences due to triangulation that deepens and widens understanding of the problem (Tashakkori \& Teddlie, 2003).

To answer the research questions, data from science class observations of teachers who participated in the two mentioned projects were analyzed in addition to data generated through interviews of students, teachers and administrators. By conducting semi-structured interviews, questions were partially driven by how the participants responded to the questions. Interviews were transcribed, coded, analyzed and interpreted by research team which conducted thematic analyses. Once all transcripts were coded, data were re-analyzed to determine the relationships 
Table 1. Class observation by school level and teacher gender

\begin{tabular}{|c|c|c|c|c|c|}
\hline & \multicolumn{4}{|c|}{ Observations } & \multirow{3}{*}{ Total } \\
\hline & \multicolumn{2}{|c|}{$\underline{\text { QIAS }^{\mathbf{a}}}$} & \multicolumn{2}{|c|}{ EPDS $^{\mathbf{b}}$} & \\
\hline & $\mathbf{F}$ & M & $\mathbf{F}$ & $\mathbf{M}$ & \\
\hline Primary $^{c}$ & 12 & - & 12 & - & 24 \\
\hline Preparatory & 10 & 8 & 8 & 7 & 33 \\
\hline Secondary & 12 & 12 & 12 & 12 & 48 \\
\hline Total & 34 & 20 & 32 & 19 & 105 \\
\hline
\end{tabular}

Theory classes ${ }^{\text {b) }}$ Practical classes ${ }^{c}$ All primary school teachers are female

Table 2. Interviewee characteristics by school and respondent

\begin{tabular}{lccccccc}
\hline \multirow{2}{*}{ Category } & \multicolumn{2}{c}{ Public schools } & \multicolumn{2}{c}{ International (Coed) } & \multirow{2}{*}{ Total } & \multirow{2}{*}{ Assigned Codes } \\
\cline { 2 - 5 } & $\mathbf{M}$ & $\mathbf{F}$ & $\mathbf{M}$ & $\mathbf{F}$ & & \multirow{2}{*}{ ( } \\
\cline { 2 - 6 } Students & 6 & 6 & 4 & 4 & 20 & MS/FS 1-20 \\
\hline Teachers & 5 & 5 & 2 & 2 & 14 & MT/FT 1-14 \\
\hline Administrators & 3 & 3 & - & - & 6 & AD1-6F/M \\
\hline Total & $\mathbf{1 4}$ & $\mathbf{1 4}$ & $\mathbf{6}$ & $\mathbf{6}$ & $\mathbf{4 0}$ & \\
\hline
\end{tabular}

Table 3. Theoretical components (QIAS)

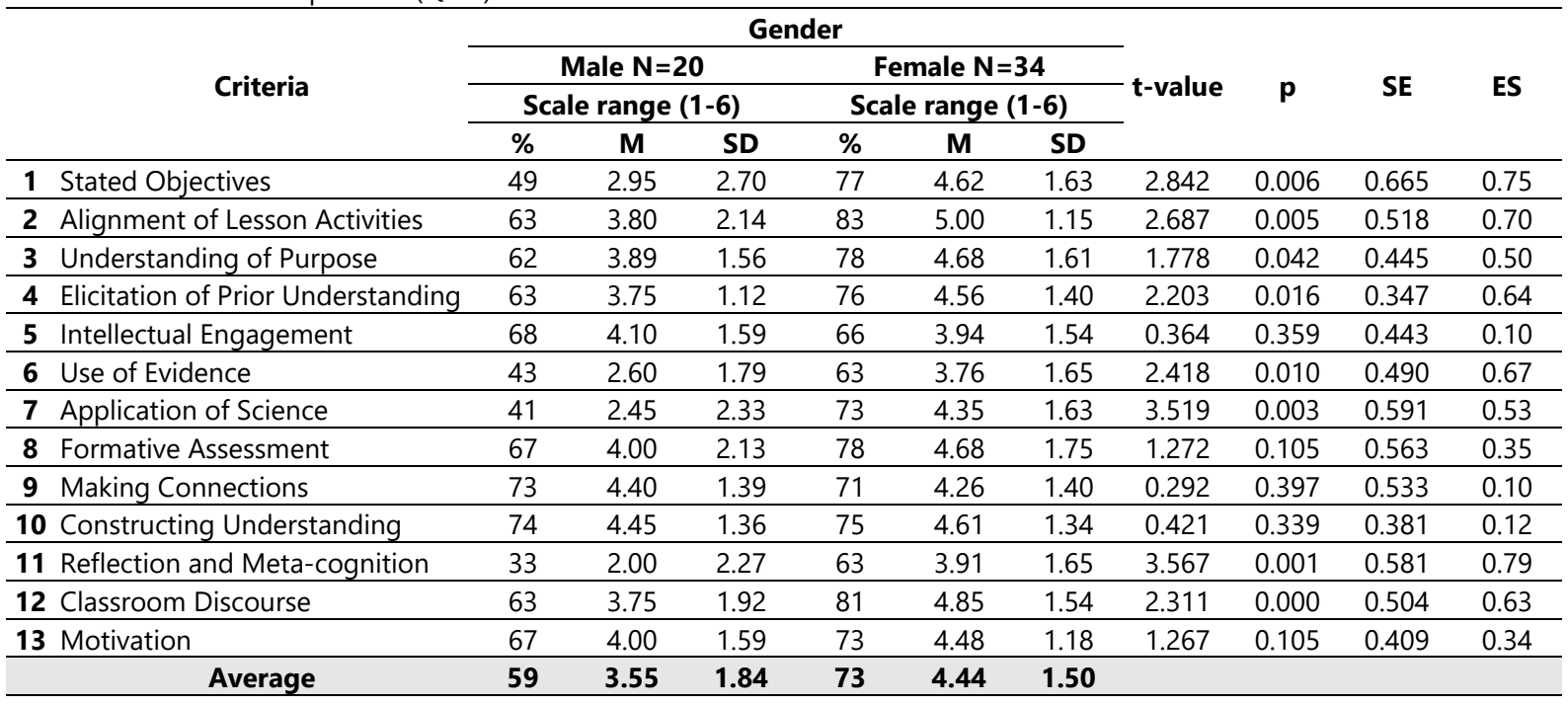

between codes and emergent themes; qualitative data from interviews and observations were then merged to help further explain the quantitative results produced.

\section{Sample}

105 teachers from 50 schools participated as part of the two projects, which have different objectives but included class observations. The distribution of classes and teachers are as in Table 1. Table 2 details the number and distribution of interviewees and their characteristics. All teachers possess science and education degrees, professional Qatari teaching licenses, and between 6-16 years of relevant experience.

\section{Class Observations}

\section{QIAS project}

54 science classes from 28 schools (2 teachers from 26 schools in addition to one teacher from each of two schools) whose teachers and students were previously surveyed, were observed using the RTOP instrument (Piburn et al., 2000). Three observers were trained by the principal investigators. The rubric uses a 4-point scale ( 0 , $2,4,6)$ for each of the 13 traits (Table 3 ). 
Table 4. Practical components (EPDS)

\begin{tabular}{|c|c|c|c|c|c|c|c|c|c|c|}
\hline \multirow{4}{*}{ Criteria } & \multicolumn{6}{|c|}{ Gender } & \multirow{4}{*}{$t$-value } & \multirow{4}{*}{$\mathbf{p}$} & \multirow{4}{*}{ SE } & \multirow{4}{*}{ ES } \\
\hline & \multirow{2}{*}{\multicolumn{3}{|c|}{$\begin{array}{c}\text { Male } \mathrm{N}=19 \\
\text { Scale range }(1-6)\end{array}$}} & \multirow{2}{*}{\multicolumn{3}{|c|}{$\begin{array}{c}\text { Female } \mathrm{N}=32 \\
\text { Scale range }(1-6)\end{array}$}} & & & & \\
\hline & & & & & & & & & & \\
\hline & $\%$ & $\mathbf{M}$ & SD & $\%$ & $\mathbf{M}$ & SD & & & & \\
\hline 1 Stated objectives & 71 & 4.26 & 0.56 & 65 & 3.98 & 1.35 & 0.867 & 0.197 & 0.267 & 0.27 \\
\hline $\begin{array}{l}2 \begin{array}{l}\text { Alignment of lesson activities to } \\
\text { objectives }\end{array} \\
\end{array}$ & 75 & 4.50 & 0.87 & 77 & 4.64 & 1.28 & 0.424 & 0.337 & 0.297 & 0.13 \\
\hline $\begin{array}{l}\text { Clarity of application and easiness of } \\
\text { performance }\end{array}$ & 67 & 4.03 & 1.42 & 79 & 4.73 & 1.27 & 1.845 & 0.036 & 0.392 & 0.52 \\
\hline $\begin{array}{l}4 \text { Understanding theoretical principles of } \\
\text { the activity }\end{array}$ & 86 & 5.13 & 1.15 & 81 & 4.88 & 1.37 & 0.673 & 0.252 & 0.353 & 0.20 \\
\hline 5 Teacher engagement & 76 & 4.58 & 0.61 & 77 & 4.59 & 1.42 & 0.029 & 0.490 & 0.281 & 0.01 \\
\hline 6 Student engagement & 67 & 4.03 & 0.87 & 71 & 4.27 & 1.15 & 0.791 & 0.194 & 0.281 & 0.24 \\
\hline 7 Helpful lab technician role & 68 & 4.11 & 0.98 & 54 & 3.23 & 1.27 & 2.613 & 0.006 & 0.313 & 0.78 \\
\hline 8 Classroom discourse & 70 & 4.18 & 1.46 & 80 & 4.83 & 1.06 & 1.866 & 0.034 & 0.381 & 0.51 \\
\hline 9 Efficient use of time & 74 & 4.42 & 1.54 & 76 & 4.55 & 1.55 & 0.294 & 0.385 & 0.442 & 0.08 \\
\hline 10 Suitability of lab for the activity & 95 & 5.68 & 0.63 & 98 & 5.86 & 0.59 & 1.040 & 0.157 & 0.176 & 0.29 \\
\hline 11 Safety & 93 & 5.61 & 1.10 & 77 & 4.59 & 1.82 & 2.221 & 0.007 & 0.401 & 0.68 \\
\hline 12 Use of technology & 89 & 5.37 & 1.26 & 85 & 5.11 & 1.65 & 0.596 & 0.277 & 0.405 & 0.18 \\
\hline 13 Sufficiency of materials and equipment & 87 & 5.21 & 1.69 & 95 & 5.67 & 0.83 & 1.332 & 0.094 & 0.413 & 0.20 \\
\hline 14 Integration with other subjects & 43 & 2.61 & 1.57 & 52 & 3.14 & 1.84 & 1.058 & 0.147 & 0.479 & 0.31 \\
\hline 15 Cooperative learning implemented & 83 & 4.97 & 1.66 & 92 & 5.53 & 0.89 & 1.670 & 0.050 & 0.410 & 0.42 \\
\hline $\begin{array}{l}16 \text { Worksheets /rovide instructions for } \\
\text { activity or experiment }\end{array}$ & 86 & 5.13 & 1.75 & 95 & 5.72 & 0.80 & 1.685 & 0.049 & 0.424 & 0.43 \\
\hline $\begin{array}{l}17 \text { Continuous feedback and assessment } \\
\text { of learning }\end{array}$ & 82 & 4.89 & 1.72 & 86 & 5.16 & 1.20 & 0.652 & 0.259 & 0.451 & 0.18 \\
\hline 18 Objectives achieved & 74 & 4.42 & 0.79 & 77 & 4.64 & 1.17 & 0.730 & 0.234 & 0.270 & 0.22 \\
\hline Average & 77 & 4.62 & 1.20 & 79 & 4.73 & 1.25 & & & & \\
\hline
\end{tabular}

\section{EDPS project}

51 teachers from 22 schools were enrolled in an 80-hour training course on the effective delivery of practical science. Teachers were observed before and after training to determine the extent to which training has impacted their delivery skills. For the purpose of this paper, only post-training observations were considered because the pre-training observations were conducted in the previous year, and the evaluation emphasized the practical aspect only. In the post training observations, the RTOP observation protocol, designed for theory-based classes, was modified to be consistent with a practical-based class environment. The evaluation rubric is an extended version of the RTOP, consisting of 18 traits to assess practical skills and practices (Table 4).

Details on distribution of the observed classes are as detailed in Table 1. It should be noted that all primary school teachers are female, irrespective of school gender.

\section{Interviews}

In order to elicit further ideas and insights, 40 interviews were conducted post-observation. The QIAS project framework included international schools, but permission to undertake an adequate number of observations was not secured from authorities. Therefore, to ensure that views from students taught by both genders were captured, interviews were conducted with students and teachers at international schools.

The main questions which guided the interviews were:

1. In your opinion, are male or female teachers better, and why?

2. Would you prefer to be taught by a male or female teacher, and why?

\section{RESULTS}

\section{Class Observations}

Means were calculated for each trait out of six points and were converted to percentages. Paired sample t-test statistical analysis was performed using IBM SPSS Statistics (version 24, 2016) to compare each trait in delivery skills between the two genders. Hedges' $\mathrm{g}$ measure of effective size was calculated for each trait to reveal the relative 


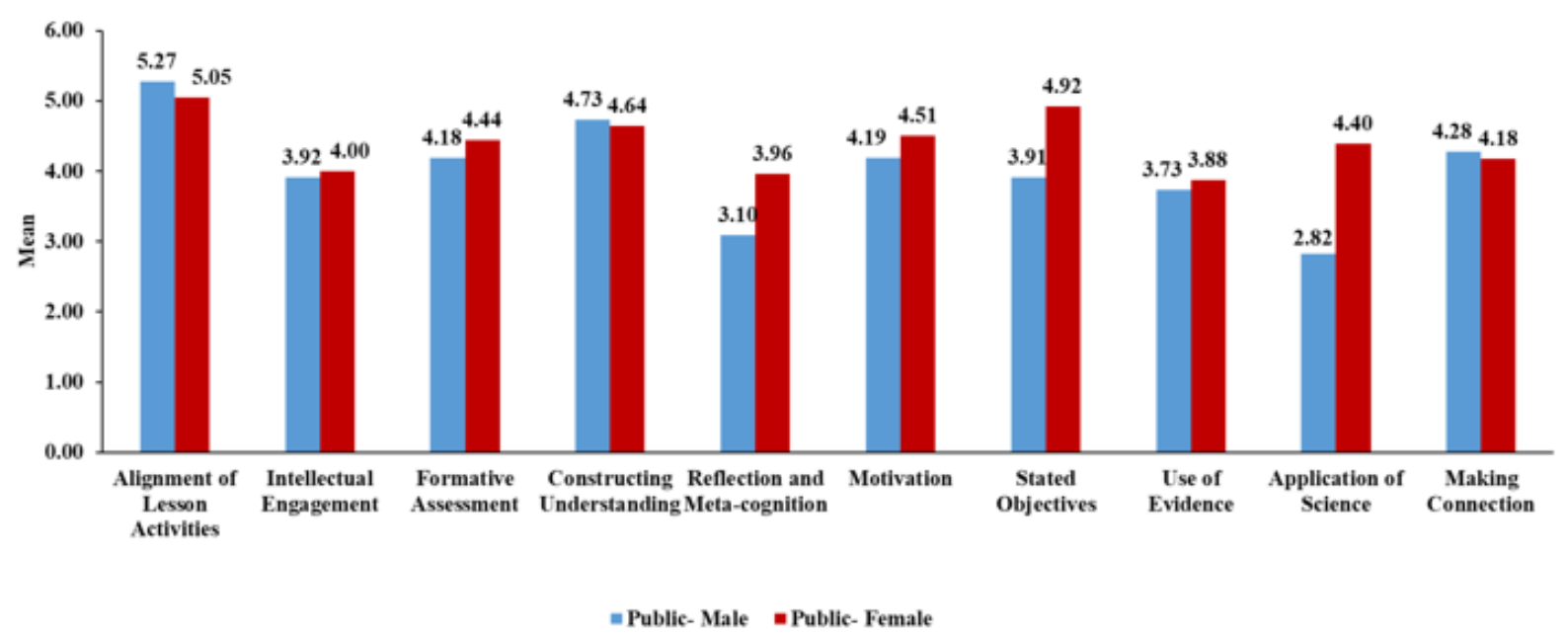

Figure 1. Science delivery skill assessment by teacher gender

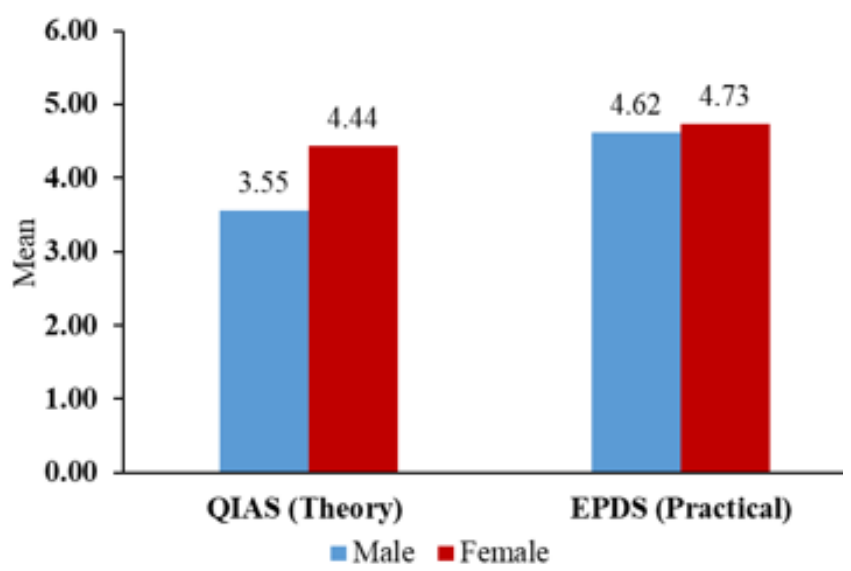

Figure 2. Science delivery skill assessment by course content

size of mean differences and the size of the effect. To determine whether a difference exists, effects were interpreted as small $(0.20-0.49)$, medium $(0.50-0.79)$, or large $(0.80$ and above). Hedges' $\mathrm{g}$ was used instead of $p$-values: though $p$-values can inform whether an effect exists, they will not reveal the size of the effect, especially when sample size is not high enough (Sullivan \& Feinn, 2012).

\section{QIAS project}

Results indicate that female teachers outperform their male counterparts in most components of delivery, particularly in relation of science to concepts of daily life and in aligning reflection and meta-cognition components. Effect size and $p$-values indicate that female teachers outperform males in eight traits with a medium level of statistical significance (ES 0.5-0.8). No significant differences were observed in the five remaining items such as intellectual engagement and constructing understanding.

Figure 1 compares aspects of delivery skills in 54 observed theoretical classes (20 male, 34 female), and detail means differences of key themes according to the RTOP rubric. Table 3 provides results on descriptive and inferential statistics, paired sample t-tests, and effect size.

The above results suggest that female teachers focus more than males on giving more examples from a 'daily life" context as observed in the "Use of Evidence" trait in Figure 1 and the statistically significant difference and large effective size ( $\mathrm{p}=0.01, \mathrm{ES}=0.67)$ (Item 6 in Table 3). This is also suggested in the "Application of Science" traits $(p=0.003, E S=0.53)$ (Item 7 in Table 3). This is consistent with Gilmartin et al. (2006) statement mentioned before.

\section{EPDS project}

Table 4 and Figure 2 summarize the results obtained from a total of 51 observed 55-minute class periods in science laboratories at schools where each teacher was delivering a science lesson and directing students' performance of a "hands-on" lab activity. The Table 4 includes the 18 traits adopted from the RTOP rubric to 
include laboratory components of the lesson. The procedure for converting the scores for each criterion to average percentage was followed as in the QIAS project. As indicated, both male and female teachers obtained comparable average scores in many criteria, but females achieved higher scores in certain criteria similar to those in the QIAS project (items 3, 5, 9, 13). However, males obtained scores in the laboratory components (items 4, 8, 12, 13, 14). Items 8 and 14, for example, are more associated with the role of the laboratory technician and availability of materials, rather than the teacher's own skills. In fact, most girls' schools in Qatar have no certified ortrained lab technicians for reasons related to the nature of the profession and salary scale; a significant gap considering that skilled laboratory technicians facilitate the conduct of good laboratory procedures.

Figure 2 summarizes the comparison between results from both the QIAS and EPDS projects. The theory classes delivered by female teachers show outperformance of female science teachers over their peers. In practical classes, the results show similar scores for delivery skills, but as shown in Table 4, the skills in delivery of practical components in laboratory classes favored male teachers.

\section{Interviews}

Interviews were analyzed using Clarke and Braun's thematic approach (2013). The data collected from interviews were clustered into five general themes that support those criteria listed in Tables 2 and 3, including some general aspects which were not addressed during the class observations, i.e. the latent themes as described by the above authors. These themes are: (a) instructional practices, (b) preparedness, (3) professional development and training needs (4) issues related to laboratories, and (5) social and cultural aspects. Narrative analysis pertinent to these themes is presented in the Discussion section.

\section{DISCUSSION}

\section{Class Observations}

Results in Table 3 indicated that few male teachers, among those observed during theory classes, began lessons by explaining the objectives of the lessons. As a result, most students do not have context for the lesson, nor are they clear on the intended focus or goal. Observation reports from theoretical classes indicate that less than half $(45 \%)$ of the males teaching theoretical classes either stated or wrote the objectives of their lesson at the beginning of class, compared with $77 \%$ of their female counterparts. Conversely, reports from practical classes indicate that handouts, almost without exception, were clear and had been written on the board at the start of the activity.

The majority of female teachers delivering theoretical classes (83\%) link the lesson with common phenomena or the class activities, giving examples of the relationship of the concepts with those activities or phenomena. After explaining and providing evidence they remind students about the lesson's objectives. Male teachers show less concern about this (ES=0.7). No significant difference was observed during the practical classes (Table 4).

\section{Reflection and metacognition}

Female teachers more frequently require students to work with peers in groups and reflect on their learning. As recorded by the observers during theory classes, female teachers more often ask their students to perform short exercises, in groups, and write questions asking students to answer after discussion with their peers. However, both genders practiced this process more frequently during laboratory classes where students are normally divided into groups based on spaces in the laboratory, with each group report their results to the whole class. As noted in Table 4, while effective size is high in favor of female teachers during theory classes, in practical classes, cooperative learning was generally implemented consistently by both male and female teachers (Item 16, Table 4).

\section{Classroom discourse}

Results show that female teachers create more frequent classroom discourse by engaging students in discussions and bidirectional communication, and allow students to express their opinions and create more student-centered learning environment $(E S=0.63)$. Several examples of this practice were recorded. One among these is the following note, recorded by the observer, about a physics class delivered by a female grade 11 teacher who was explaining to her students the concept of heat transfer between hot and cold bodies:

After elicitation of prior knowledge, the teacher displayed a slide showing a student mixing two equal -volume beakers of the same liquid $(X)$, a hot one at 70 degrees centigrade and the other at $25^{\circ} \mathrm{C}$. She asked the students to find the temperature of the mixture. Students were allowed to discuss the answer with their peers. After 2 minutes no one answer, she asked "what information is missing? One student answered" the mass of liquid in each beaker; she wrote the values of the two masses. A student then raised his hand after few minutes, giving her the answer; she wrote it and asked the class "who agree? few students 
agreed, then one student said" another information is missing Ms. The specific heat of the liquid, the first student said it is 1.0, the other student replied"1.0" is only for water, she wrote the value of the specific heat. After a few minutes most students were able to give the correct answer.

In another observation report the following note was recorded from a male grade 11 physics class on Newton's second law "The teacher wrote the expression of the velocity, mass and acceleration on the board directly, then wrote an example and asked students to calculate the value of acceleration". In a female class on the same topic, the report stated "The teacher wrote the three terms asked students about the definition of each concept, derived the relationship from the definitions and asked students to calculate the acceleration".

\section{Elicitation of prior knowledge}

Female teachers tend to ask their students questions about their prior knowledge of the topic of the lesson before starting; in few cases teachers wrote a multiple-choice question on the board asking students to rate their knowledge of concepts by selecting a number reflecting their level of prior knowledge. Some reviewed main concepts from previous lessons. Fewer male teachers practice this assessment or review; they prefer to start lecturing directly. Table 4 shows that difference reflected in a medium effective size (0.64), low standard deviation and standard error.

\section{Formative assessment and feedback}

Generally speaking, the study found that both male and female teachers use little assessment during theory classes, although female teachers ask students more often to monitor learning (ES=0.35), this gap is more reduced in the practical classes $(E S=0.18)$ as the nature of the practical activity, generally, requires asking questions especially at the end of the activity.

\section{Laboratory and safety considerations}

The differences in laboratory skills and management issues reflect differences in attitude toward conducting practical science, which is mainly due to feeling less confident in dealing with technological instruments (Brotman \& Moore, 2008; Gecer \& Zengin, 2015). This is also reflected on the attitude of their students. In our EPDS project, we noticed this significant difference as well. When the students were surveyed before and after training of their teachers, although a significant increase in both variables was observed, the t-test analysis, to find out the extent of these variations for each gender before and after training, shows that improvement is more favored in the case of male students (Said, Adam, \& Abu-Hannieh, 2018b).

In one particular experiment in grade 11 chemistry on reactions of alcohols which involve many chemicals, four teachers from each gender were observed. The observers' supplementary notes indicate that three female teachers did not perform the hands-on activity in the lab, and the experiment was only demonstrated using a video virtual lab, while three classes of male teachers performed the experiment successfully and only one teacher opted for the virtual lab demonstration. The same trend was observed in one biology experiment. In the topic on structure and function of the heart, the curriculum standard recommended that teachers either perform a dissection experiment of a sheep's heart or demonstrate on a model. The four male teachers opted for the sheep's heart while the four female teachers chose the model.

The above notwithstanding, female teachers were generally more knowledgeable and capable of teaching other biology topics than male teachers. During the assessment of the 24 secondary school teacher trainees in the EDPS project, both experiment competence and subject knowledge were assessed. It was found that female teachers outperform their male colleagues in biology and physics content knowledge, while males outperformed female teachers in chemistry knowledge. The same trend was observed among the control teachers who had taken the same test. In the assessment on conducting experiments, the opposite trend was observed: male teachers outperformed females in chemistry and physics while females outperformed males in the biology. However, it is difficult to draw a conclusion from the results of this part due to the small number of teachers in each subject.

The results shown in Table 4 indicate that male teachers are more aware of safety during practical classes. Observation reports showed that male teachers followed the safety instructions more appropriately than female teachers. Certain incidents were reported such as during an observation of a grade 10 chemistry class when a student who splashed a chemical on her peer's worksheet at the bench was unobserved by the teacher. On the contrary, almost all male teachers had written safety rules and precautions or displayed them on the board, and warned students about all possible safety hazards. Also, all chemistry teachers and their students in male schools were wearing safety glasses in the laboratory, while several female students were observed without glasses. 14 female students from different schools were noticed chewing in the chemistry lab (including 3 from the same class) 
Table 5. Differences in performance in science classrooms by gender

\begin{tabular}{lcccc}
\hline \multirow{2}{*}{ Criteria } & \multicolumn{2}{c}{ Theory } & \multicolumn{2}{c}{ Practical } \\
\cline { 2 - 5 } & \multicolumn{2}{c}{ Significance of difference in favor of } \\
\cline { 2 - 5 } Stated objectives & Male & Female & Male & Female \\
\hline Alignment of lesson activities & - & Medium & - & Small \\
\hline Understanding of purpose & - & Medium & Nil & Nil \\
\hline Use of evidence/student engagement & - & Medium & - & Small \\
\hline Application of science & - & Medium & & Small \\
\hline Formative Assessment & - & Medium & & Medium \\
\hline Reflection and meta-cognition/cooperative learning & - & Small & Nil & Nil \\
\hline Classroom discourse & - & High & & Medium \\
\hline Helpfulness of lab technician role & - & Medium & - & Medium \\
\hline Safety considerations & NA & NA & Large & - \\
\hline Cooperative learning implemented & NA & NA & Medium & - \\
\hline
\end{tabular}

without being warned, compared with only 4 male students from all male schools. Chewing is prohibited in all science laboratories for safety considerations.

One main factor that affected the effectiveness of teachers' delivery of practical classes is the role of the lab technician. This role is critical in facilitating the conduct of successful laboratory classes. Most schools employ science teachers as lab technicians. These are mostly untrained and lack laboratory management skills. However, male lab technicians observed together with teachers during the lab classes were found more helpful during the classes than the female lab technicians with a significant difference $(p=0.005, E S=0.78)$ with low standard deviations.

Based on results in Tables 3 and 4, a summary difference in delivery skills between male and female teachers in science classroom is shown in Table 5.

\section{Interviews}

The forty interviews conducted were analyzed by a thematic approach to explore further themes not addressed during class observations. Brief summaries of these themes are presented below.

\section{Instructional practices and pedagogy}

Addressing the main question on the difference in teaching styles and delivery skills, the six administrative participants agreed that female teachers outperform males in theory classes. This theme includes teaching strategies, activities, motivations,

homework and assessment.

\section{Interview Category Support Quotations}

Female Vice Principals "Female teachers are hardworking and more patient."

Female Vice Principals (AD1F: female vice principal/chemistry certified trainer)

Male Vice Principals Females prepare well, they are organized, assess more than males, give feedback very often." (AD6M: male vice principal)

"We normally look into details and ask more questions, I was teaching in an international school before, I

Female Teachers attended several classes for some of my male colleagues, most of them like to start directly lecturing from the beginning of the lesson, men tend to give more topics in a period while women like to explain more and ask questions." (FT1: female Grade 11 teacher)

"We have a very long curriculum that must be completed, and it is difficult to spend time on more discussions or group cooperative learning or even perform many laboratory activities. We need to balance between theory and

Male Teachers activities, and sometimes you find students get bored from lectures. Our female colleagues spend more time on discussion, revisions and answering students' questions; this is why at the end of the year they try to compensate and give extra classes." (MT1: male Grade 12 chemistry teacher)

"I was taught by four different science teachers before, two females and two males, I found female teachers focus on discussions and questions, but they are less confident than male teachers when they answer questions or perform lab activities." (FS1: female Grade 12 international school student)

Female Students "I enjoy science lessons because I like the teacher's style, she motivates us and always divides class into groups to answer questions and solve problems, and she is patient and passionate. Science is difficult, but she made it easy for us." (FS3: female grade 9 public school student)

"Every class our teacher allocates time for discussion or learning something new." (FS4: female Grade 10 student)

"She discusses more often, interacts with all, answers all questions and respects students' opinions. A male Male Students teacher, although good in lectures and labs, doesn't encourage much discussion or answers all questions, he is more strict and provides less motivation." (MS2: male Grade 11 international school student).

Comments from these interviews agreed with the class observations' results on this theme, as was noticed earlier (reflection and metacognition section) and also Table 3 which shows that female teachers extensively use 
cooperative and group learning (item 11). This is also in line with the recommendations of learning and teaching principles of project 2061 initiative which emphasizes group learning approach (American Association for the Advancement of Science 1990).

\section{Inadequate preparation in mathematics and scientific expressions}

A common problem reported by both teachers and students was that of inadequate preparation in mathematics and scientific expression - both teachers' lack of the required skills and students' lack of knowledge in mathematics required for understanding science concepts and principles:

Interviewee Category Support Quotations

Female Teachers "This is a major barrier towards learning physics. Most students who perform poorly in physics lack basic skills in mathematics. When I explain certain topics, I spend ample time explaining mathematics or algebra." (FT5: female physics teacher)

Male Teachers "Mathematics issues are common for all students with no exception. There is something wrong in teaching mathematics." (MT6: male chemistry teacher)

"I spent two lessons explaining to students this topic but only few students can practice them, and even when they practice, they cannot do them during the tests, these are above secondary school levels." (MT4: male chemistry teacher talking about difficulty of explaining how to balance oxidation -reduction equations. See quotes of FS5 and MS6 below.)

Female Students "The chemistry teacher asked us to memorize many things including some difficult reaction equations. For example, oxidation reduction equations are difficult to memorize. There should be some rules to practice, she told us the rules are complicated, and that memorizing is the easiest way to remember them." (FS5: female Grade 11 student)

"The good thing about our physics teacher is that she is very good in mathematics and she simplifies the complex physics equations." (FS7: female Grade 11 student).

Male Students "I love chemistry, I enjoyed everything especially when we practice in the lab, but when it comes to balancing these complicated equations, I become stuck; also, I am not good in complicated stoichiometric problems because I am not good in mathematics." (MS6: male Grade 11 student)

It is difficult to believe students can successfully study science without a sound understanding of the mathematics underpinning scientific principles and concepts. The main problem in Qatar, as everywhere among low achieving countries in science, is the weak links across mathematics, science and technology (McCormick \& Murphy 1998). Boohan (2016) attributed the failure or low achievement in science by students, partly, to the lack of the mathematical skills and how to adopt understanding of mathematics lessons to a science-learning context. Shumow and Schmidt (2014) identified mathematics anxiety as a distinct form of anxiety which plays a negative role in science learning. Also, mathematics achievement of Qatari students, in general, is low in international tests (Mullis et al., 2016; OECD, 2018b).

An example of the impact of poor mathematical skills on understanding the extent of a chemical reaction by representing the reaction with a graph that reflects the variation of reaction rate with time. To understand this relationship, the student needs to know how the gradient and the shape of a graph reflect the progress with time. This example shows the significance of the link between chemistry and mathematics. Similar links with other science subjects are vital for science understanding.

The comments of students and teachers indicate that this lack of skills is common among both genders' schools. This is probably a result of the lack of connection between mathematics and science teaching as mentioned above.

\section{Social and cultural aspects}

Recently published statistical figures from Ministry of Education and Higher Education (MoEHE) indicate that as low as 230 male Qatari teachers and 3,721 female teachers are now in in public schools (MoEHE, 2017). In addition, a majority of science teachers are non-Qatari. The following quotations explain the reasons behind this decline in pursuing teaching careers, especially in science.

Interviewee Category Support Quotations

Male Principal / Vice "Most males here in Qatar do not like teaching jobs - especially science and math - this is why we don't have Principal

many male teachers, they prefer to work in high managerial professions, in business or as military officers. Therefore, they don't have passion for teaching; most females, however, have passion for teaching which is associated with cultural and social issues that characterize a conservative society." (AD2M: male principal) "Cultural issues are very sensitive, not only students feel uncomfortable being taught by an opposite gender, teachers as well feel the same. Male teachers are normally less patient and stricter than female teachers, female students are very sensitive, and teachers would avoid too much arguments with them." (AD3M: male principal/biology certified teacher)

Female Teachers "Children feel that we are like their mothers and they trust us that we care about them more than male teachers, science activities for them are fun and they enjoy them more with us." (FT2: female teacher in a boys' school)

Male Teachers "You rarely find a female teacher worried about financial issues; on the contrary most male teachers are concerned and look for extra earning through private tutoring; therefore, they put more efforts on private tutoring." (MT8: male science coordinator/teacher) 
Female Students

Male Students
"I definitely feel more comfortable when I am taught by female teachers; they understand us better than men. I don't feel embarrassed talking to her but of course not all of them." (SF4: female Grade 12 student)

"I was more interested in science lessons before, our [female] teachers were more helpful and patient, now sometimes I don't understand some concepts but am hesitant to ask my male teacher. Our previous [female] teachers listened more to us." (MS5: male student)

\section{Laboratory and safety issues}

As earlier noted in Table 4, a gap in practical activity delivery skills was noted when analyzing lab-based classes.

\section{Interviewee Category Support Quotations}

Male Principals and "It is common that female teachers' interaction with technology and equipment is more cautious. Men are more Vice Principals skilled and confident in dealing with equipment and safety issues. Men face less difficulty in obtaining materials from different sources if they are not available at schools. Female teachers have less access to these things." (AD3M: male vice principal)

"Females are hesitant in practical labs, especially in chemistry, most of them lack experience so they tend to give few practical activities, but they show students more videos and animations. They however, give more critical thinking activities than male teachers do." (AD2M: male principal)

Female Teachers "We are cautious because parents are more worried about their daughters, some of them request us to exclude their daughters from some activities especially in chemistry. At one incident, my colleague was demonstrating to students in the lab some properties of acids and bases, she started telling them that acids have sharp taste, she brought very dilute acids and base to demonstrate an experiment, later in the class, a grade 7 student tried to taste the acid which was placed on the bench. I wrote the incident, and from that date the administration refused to provide the lab with any chemical even those needed for grades 8 and 9." (FT11: female preparatory school science teacher)

Male Teachers "Certain experiments in physics at secondary school level require some safety as well. For example, working with stroboscopes are sometimes dangerous and require high precautions especially if a student is suffering from epilepsy. In electricity also using high voltage generators may cause some danger of a shock. Therefore, teachers, especially females, avoid such experiments and demonstrate using videos." (MT10: male physics teacher)

\section{Preparedness}

\section{Interviewee Category Support Quotations}

Female Principals and "Female teachers work harder and prepare well before they go to classes, we have a coordinator for each subject Vice Principals meets with all teachers and review their weekly plan and discuss with them major points and sometimes they arrange coaching. You don't see this in boys' schools. Male teachers generally begin classes with minimum preparation." (AD4F: female principal/science teacher)

"From my experience as a trainer, I found females have better commitments, more punctual than male teachers, they give more homework to their students. However, we also found that male teachers have more knowledge about the contents and more familiar with the practical part of the subjects." (AD3M: female vice principal/biology trainer)

"According to recommendations of the science curriculum the required weekly assignment should be about half the number of contact class hours that is about 2 assignments per week. Most female teachers conform to this recommendation while male teachers tend to lower this number, therefore you find that female students are more engaged, read more on the subjects and perform better". You probably noticed that the majority of top-ranking students in grade 12 state exam are from female schools." (AD1F: female vice principal/trainer)

Female Teachers "We think that children at primary and preparatory levels enjoy biology more than physics and chemistry, they expect us to provide them with details, and they enjoy watching videos and like the photographs and pictures, so we have to read more and look for details. Male teachers like to explain without details and also they give less assignments. My son who is in grade 9 rarely brings homework with him in science: teachers give them easy tasks to do in class." (FT10: female preparatory teacher)

Male Teachers "Males mostly depend on their experience. We don't have time to prepare in detail, in chemistry we are more confident than female teachers especially in the laboratory, We have better skills. However, female teachers read and prepare better than us. In preparatory schools, general science curriculum includes more biology and easier practical activities, female teachers are more knowledgeable and confident." (MT9: male Grade 9 chemistry teacher)

Male Student "Our science teacher gives us some long questions once a week, asks us to solve them at home and bring them back. He just marks and returns them, mostly with few feedback comments inside". (MS7: male preparatory student) 


\section{Laboratory technician issues}

Most schools' lab technicians are science teachers who either were employed as lab technicians or they were science teachers and become lab technicians, mostly for more comfortable duties.

\section{Interviewee Category Support Quotations}

Male Principals and "Lab technicians support the science teachers to perform practical experiments, maintain good housing, make Vice Principals orders for materials or glassware with no other responsibility such as preparing tests or marking or meeting parents, etc. an easy job although so many contact hours. Therefore, most Qatari science teachers, especially men, prefer to work as technicians, the salary is only 10-15\% less than that of the teacher." Asked why the men lab technicians are more skilled, he explained "most men lab technicians are non-Qatari Arab nationals who are more skilled than women in dealing with equipment and chemicals also they control students more than women do, they are more capable of providing or buying materials if they are not available at schools." (AD6M: male vice principal)

Female Teachers "Female lab technicians are not trained and lack familiarity, knowledge and skills in lab management. We are also less prepared than male teachers, our main concern is safety of students and parents concern, and we face a difficulty in managing students' behavior in the lab." (FT12: female preparatory school teacher)

\section{Professional development of teachers}

In a previous publication by the authors that included results from a survey of 175 science teachers on barriers to performing effective science laboratory classes (Said, 2014), teachers ranked their insufficient experience as second among twelve major barriers. Most of the teachers interviewed for this research, both males and females, agreed that their professional development, which is planned and organized by the development office at the Ministry of Education and Higher Education, is more centered about general educational issues with little on subject specialties.

\section{Interviewee Category Support Quotations}

Female Principals and "The main problem in arranging professional development for teachers is the shortage of teachers who can Vice Principals substitute trainees' classes during the working hours, the Ministry now prohibits any training after school working hours, and it is difficult to release them during classes' period." (AD5F female vice principal)

Male Principals and "The Ministry sometimes arranges workshops for subjects' teachers but mostly focus on implementing Vice Principals curriculum standards not on real knowledge contents or lab activities. I was a trainer on some of them, these workshops sometimes are carried out over few days. From my experience I found that these workshops would be more beneficial if they were supported by intensive practical activities, not only for teachers but also for lab technicians especially for female teachers who need to deepen their knowledge and practical skills while male teachers lack pedagogical and organizational skills." (AD3M: male vice principal/ biology trainer)

Male Teachers "Most of the professional development and training workshops are focused on pedagogical aspects, with only a few short training workshops are devoted to content knowledge or practical hands-on-activities." (MT13: male teacher)

This lack of hands-on-activities in professional development is reflected on teaching practices that teachers impose in their delivery of science classes. Teaching should be consistent with the nature of scientific inquiry and active students' engagement; and teachers should be trained on these practices (American Association for the Advancement of Science 1990), Millar, and Abraham, (2009).

\section{Implications for further studies}

An important aspect that needs to be further explored is the impact of demographic aspects on teaching styles in science-related disciplines. For example, the number of years in the profession, the geographical areas of schools, availability of teaching resources, access to technology, laboratory suitability, number of students and the opportunities of professional development are key factors that can mitigate or exacerbate the effect of gender on teaching effectiveness. One further aspect is the level of mathematical skills of the teacher and his or her ability to adapt these skills in science contexts.

In conclusion, the findings from this study do not provide robust evidence of better teaching styles between genders in relation to theoretical or practical science lesson delivery; however, the data indicate general common features generally attributable to each. For example, female teaching styles tend to be characterized by active questioning, discussions, more motivation and interaction with students, whereas male teaching styles are characterized by lecturing, less homework and better performance in lab-based classes. Other factors play important roles in shaping teachers' styles, including school policy, class environment and resource availability.

\section{ACKNOWLEDGEMENTS}

The NPRP 8-503-5-065 team members would like to thank the Qatar National Research Fund for the generous support of this research through the National Priority Research Program. Any opinions, findings and conclusions or recommendations expressed in this report are those of the principle investigators and do not necessarily reflect the views of the Qatar National Research Fund; QNRF has not approved or endorsed its content. We would also like to thank the many students, teachers, administrators, and staff who made this study possible. We deeply appreciate their contributions and professionalism. 


\section{REFERENCES}

Abd El Khalick, F., Boujaoude, S., Duschl, R., Lederman, N. G., Mamlok-Naaman, R., Hofstein, A., ... Tuan, H. L. (2004). Inquiry in science education: International perspectives. Science Education, 88(3), 397-419. https:// doi.org/10.1002/sce.10118

American Association for the Advancement of Science (1990). Effective Learning and Teaching; Teaching Science, Mathematics, and Technology. Retrieved from http://www.project2061.org/publications/sfaa/online/ Chap13.htm

American Association for the Advancement of Science. (1998). Blueprints for Reform: Science, Mathematics, and Technology Education. New York: Oxford University Press, 1998.

Basow, S. A. (1999). Student evaluations of college professors: When gender matters. Journal of Educational Psychology 87(4), 656-65. https:/ / doi.org/10.1037/0022-0663.87.4.656

Boohan, R. (2016). The Language of Mathematics in Science: A Guide for Teachers of 11-16 Science. The Association for Science Education, Nuffield Foundation. Retrieved from https://www.ase.org.uk/mathsinscience

Bottia, M. C., Stearns, E., Mickelson, R. A., Moller, S., \& Valentinoc, L. (2015). Growing the Roots of STEM Majors: Female Math and Science High School Faculty and the Participation of Students in STEM. Working paper series No. 103. https:/ / doi.org/10.1016/j.econedurev.2015.01.002

BouJaoude, S., \& Gholam, G. (2013). Gender and science in the Arab states: current status and future prospects. In N. Mansour \& R. Wegerif (Eds.), Science Education and Diversity (pp. 339-358). New York, NY: Springer. https://doi.org/10.1007/978-94-007-4563-6_17

Brotman, J. S., \& Moore, F. M. (2008) Girls and science: A review of four themes in the science education literature. J. Research in Science Teaching, (45), 971-1082. https:// doi.org/10.1002/tea.20241

Carrington, B., Tymms, P., \& Merrell, C. (2008). Role models, school improvement and the 'gender gap' - do menbring out the best in boys and women the best in girls? British Educational Research Journal, 34(3), 315327. https:/ / doi.org/10.1080/01411920701532202

Centra, J. A., \& Gaubatz, N. B. (1998). Is there gender bias in student ratings of instruction? Journal of Higher Education, 70, 17-33. https:/ / doi.org/10.1080/00221546.2000.11780814

Clarke, V., \& Braun, V. (2013) Teaching thematic analysis: Overcoming challenges and developing strategies for effective learning. The Psychologist, 26(2), 120-123.

Driver, R., Leach, J., Millar, R., \& Scott, P. (2007). Young people's images of science. Bristol, PA: Open University Press.

Feldman, K. A. (1992). College students' view of male and female college teachers: Part I-Evidence from the social laboratory and experiments. Research in Higher Education, 33, 317-75. https:/ / doi.org/10.1007/BF00992265

Francis, B., Skelton, C., Carrington, B., Hutchings, M., Read B., \& Hall I. (2006). A Perfect Match? Pupils' and teachers' views of the impact of matching educators and learners by gender. Paper presented at the British Educational Research Association Annual Conference, University of Warwick, 6-9 September 2006.

Gall, M. D., Borg, W. R., \& Gall, J. P. (1996). Educational research: An introduction, White Plains. NY: Longman, 1996.

Galloway, K. R., \& Bretz, S. L. (2015). Measuring Meaningful Learning in the Undergraduate General Chemistry and Organic Chemistry Laboratories: A Longitudinal Study. J. Chem. Educ., 92(12), 2019-2030. https://doi.org/10.1021/acs.jchemed.5b00538

Gardner, P. L. (1975). Attitudes to science. Studies in Science Education, 2, 1-41. https:/ / doi.org/10.1080/03057267508559818

Gilmartin, S., Denson, N., Li, E., Bryant, A., \& Aschbacher P. (2007). Gender ratios in high school science departments: The effect of percent female faculty on multiple dimensions of students' science identities. Journal of Research in Science Teaching, 44(7), 980-1009. https:/ / doi.org/10.1002/ tea.20179

Greene, J. C. (2007). Mixed methods in social inquiry. San Francisco, CA: Jossey-Bass.

Griffith, A. (2010). Persistence of women and minorities in STEM field majors: Is it the school that matters? Economics of Education Review, 29(6), 911-922. https:/ / doi.org/10.1016/j.econedurev.2010.06.010

Hofstein, A., \& Lunetta, V. N. (2004). The laboratory in science education: foundation for the 21st century. Science Education, 88, 28-54. https://doi.org/10.1002/sce.10106

Ibe, J. O., Adah, S. A., \& Ihejiamaizu, C. C. (2013). Assessment of Secondary School Chemistry Teachers' Quality through Identification and Use of Laboratory Apparatus in Cross. Journal of Education and Practice, 4(5).

Islahi, F., \& Nasreen (2013) Who Make Effective Teachers, Men or Women? An Indian Perspective. Universal Journal of Educational Research, 1(4), 285-293. https:/ / doi.org/10.13189/ujer.2013.010402 
Koballa, T. R. (1995). Learning science in the schools: Research reforming practice. In S. M. Glynn \& R. Duit (Eds.), Children's attitudes toward learning science (pp. 59-84).

Lacey, C. H., Saleh, A., \& Gorman, R. (1998). Teaching nine to five: A study of the teaching styles of male and female professors. Paper presented at the Annual Women in Educational Leadership Annual Conference. Nebraska October 11-12.

Lim, J., \& Meer, J. (2017). The Impact of Teacher-Student Gender Matches, Random Assignment Evidence from South Korea. Journal of Human Resources, 52(4), 979-997. https:/ / doi.org/10.3368/jhr.52.4.1215-7585R1

Martin, A., \& Marsh, H. (2005). Motivating boys and motivating girls: Does teacher gender really make a difference? Australian Journal of Education, 49(3), 320-334. https:/ / doi.org/10.1177/000494410504900308

Martin, M. O., Mullis, I. V. S., Foy, P., \& Hooper, M. (2016). TIMSS 2015 International results in science. Retrieved from Boston College, TIMSS \& PIRLS International Study Center website: http:/ / timssandpirls.bc.edu/timss2015/international-results/

McCormick, R., \& Murphy, P. (1998). The Use of Mathematics in Science and Technology Education, Perspectives and Issues. Paper presented at the British Educational Research Association Annual Conference, The Queen's University of Belfast, Northern Ireland, 27th - 30th August 1998. Retrieved from http:/ / www.leeds.ac.uk/educol/documents/000000807.htm

Millar, R., \& Abraham, I. (2009). Practical Work: making it more effective. Science School Research, 91(334), 59-64.

Mullis, I. V. S., Martin, M. O., \& Loveless, T. (2016). 20 Years of TIMSS: International Trends in Mathematics and Science Achievement, Curriculum, and Instruction. Chestnut Hill, MA: TIMSS \& PIRLS International Study Center, Boston College. Retrieved from http:/ / timss2015.org/timss2015/wp-content/uploads/2016/T15-20-yearsof-TIMSS.pdf

Novak, J. D. (2011). A Theory of education: meaningful learning underlies the constructive integration of thinking, feeling, and acting leading to empowerment and responsibility. Meaningful learning Review, 1, 1-14.

OECD. (2016a). PISA 2015 Assessment and Analytical Framework: Science, Reading, Mathematic and Financial Literacy, PISA, OECD Publishing, Paris. Retrieved from https://www.mecd.gob.es/dctm/inee/internacional/pisa2015-frameworks.pdf?documentId=0901e72b820fee 48

OECD. (2016b). PISA 2015 Results in focus. Retrieved from https://www.oecd.org/pisa/pisa-2015-results-infocus.pdf

OECD. (2018a). Education GPS. Retrieved from http:/ / gpseducation.oecd.org

OECD. (2018b). Country profile, Qatar. Retrieved from http://gpseducation.oecd.org/CountryProfile? primaryCountry $=$ QAT\&treshold $=10 \&$ topic $=$ PI

Osborne, J., Simon, S., \& Collins, S. (2003). Attitude towards science: A review of the literature and its implications. International Journal of Science Education, 25(9), 1049-1079. https:/ / doi.org/10.1080/0950069032000032199

Piburn, M., Sawada, D., Falconar, K. Truly, J. Benford, R., \& Bloom, I. (2000). Reformed Teaching Observation Protocol (RTOP). Technical Report No. IN00-1 Arizona Collaborative for Excellence in the Preparation of Teachers (ACEPT) Retrieved from https://mathed.asu.edu/instruments/rtop/RTOP_Reference_Manual.pdf.

Russell, C., \& Weaver, G. (2008). Student Perceptions of the Purpose and Function of the Laboratory in Science: A Grounded Theory Study. International Journal for the Scholarship of Teaching and Learning, 2(2). https:/ / doi.org/10.20429/ijsotl.2008.020209

Said, Z. (2016). Science Education Reform in Qatar: Progress and Challenges. Eurasia Journal of Mathematics, Science E Technology Education, 12(8), 2253-2265. https:/ / doi.org/10.12973/eurasia.2016.1301a

Said, Z. (July 2014) The Importance of Practical Activities in School Science: Perspectives of Independent School Teachers in Qatari Schools. The 5th International Conference on Education and New Learning Technologies EDULEARN13, Barcelona, Spain. Proceedings, 4847-4856.

Said, Z., \& Al-Amadi, A. (2018a). The Role of Family Engagement in Students' Science Learning In Qatarı Schools. The Eurasia Proceedings of Educational \& Social Sciences (EPESS), 11, 142-152.

Said, Z., Adam, E., \& Abu-Hannieh, A. (2018b). Enhancement of School Students' Interest in, and Attitude toward Science by Training Their Teachers on Effective Delivery of Practical Activities. The Eurasia Proceedings of Educational \& Social Sciences (EPESS), 9, 52-58.

Said, Z., Al-Emadi, A. A., Friesen, H. L., \& Adam, E. (2018). Assessing the Science Interest, Attitude, and SelfEfficacy of Qatari Students at the Preparatory, Secondary, and University Levels. Eurasia Journal of Mathematics, Science \& Technology Education, 14(12), em1618._https:/ / doi.org/10.29333/ ejmste/94733

Said, Z., Anwari, M., Al-Shahrouri, H., \& Adam, E. (2018c). Impact of Long Training Course for Science Teachers on Their Delivery Skills of Practical Science. Proceedings of International Conference of Education, Research and 
Innovation ICERI2018, 12th-14th November 2018, Seville, Spain. The International Academy of Technology, Education and Development (IATED), 8168-8174. https:/ / doi.org/10.21125/iceri.2018.0476

Said, Z., Summers, R., Abd-el-Khalick, F., \& Wang, S. (2016b). Attitudes toward science among grades 3 through 12 Arab students in Qatar: findings from a cross-sectional national study. International Journal of Science Education, 38(4), 621-643. https:/ / doi.org/10.1080/09500693.2016.1156184

Schibeci, R. A. (1984). Attitudes to science: An update. Studies in Science Education, 11, 26-59. https:/ / doi.org/10.1080/03057268408559913

Sellami, A., Kimmel, L., Wittrock, J., Hunscher, B., Cotter, A., Al-Emadi, A., \& Al-Emadi, D. (2017). Factors shaping Qatari students' career expectations in STEM, business, or public sectors fields. Eurasia Journal of Mathematics, Science E Technology Education, 13(10), 6491-6505. https:/ / doi.org/10.12973/ ejmste/77043

Shumow, L., \& Schmidt, J. A. (2014). Enhancing Adolescents' Motivation for Science SAGE publications, Thousand Oaks, California (p. 127).

Strati, A. D., \& Schmidt, J. A. (2013). Exploring the role of teacher challenge and support in high school general science classrooms. The annual meeting of the American Educational Research Association, San Francisco, April, 2012.

Sullivan, G. M., \& Feinn, R. (2012). Using Effect Size-or Why the $p$ value is Not Enough. Journal of Graduate Medical Education, 4(3), 279-282. https:/ / doi.org/10.4300/JGME-D-12-00156.1

Tashakkori A., \& Teddle, C. (2003). Handbook of mixed methods in social and behavioral research. Thousand Oaks, CA: Sage.

Wentzel, K. R., Battle, A., Russel, S. L., \& Loony, L.B. (2010). Social supports from teachers and peers as predictors of academic and social motivating. Contemporary Psychology, 35(3), 193-202. https://doi.org/10.1016/j.cedpsych.2010.03.002

Wood, T. D. (2012). Teacher Perceptions of Gender-Based Differences among Elementary School Teachers. International Electronic Journal of Elementary Education, 4(2), 317-345.

\section{http://www.ejmste.com}

